\title{
Cellular approaches to central nervous system remyelination stimulation: thyroid hormone to promote myelin repair via endogenous stem and precursor cells
}

\author{
Laura Calzà $^{1,2}$, Mercedes Fernandez ${ }^{1}$ and Luciana Giardino ${ }^{1,2}$ \\ ${ }^{1}$ BioPharmaNet-DIMORFIPA and ${ }^{2}$ National Institute of Biostructures and Biosystems, University of Bologna, Via Tolara di Sopra 50 , 40064 Ozzano Emilia, Bologna, Italy \\ (Correspondence should be addressed to L Calzà at BioPharmaNet-DIMORFIPA, University of Bologna; Email: laura.calza @ unibo.it)
}

\begin{abstract}
Brain and spinal cord repair is a very difficult task in view of the extremely limited repair capability of the mature central nervous system (CNS). Thus, cellular therapies are regarded as a new frontier for both acute and chronic neurological diseases characterized by neuron or oligodendroglia degeneration. Although cell replacement has been considered as the primary goal of such approaches, in recent years greater attention has been devoted to the possibility that new undifferentiated cells in damaged nervous tissue might also act in autocrine-paracrine fashion, regulating the microenvironment through the release of growth factor and cytokines, also regulating immune response and local inflammation. In this review, repair of demyelinating disease using endogenous cells will be discussed in view of the critical role played by thyroid hormones (THs) during developmental myelination, focusing on the following points: 1) endogenous stem and precursor cells during demyelinating diseases; 2) TH homeostasis in the CNS; 3) cellular and molecular mechanism regulated by TH during developmental myelination and 4) a working hypothesis to develop a rationale for the use of THs to improve remyelination through endogenous stem and precursor cells in the course of demyelinating diseases.
\end{abstract}

Journal of Molecular Endocrinology (2010) 44, 13-23

\section{Introduction}

Brain and spinal cord lesions have an extremely limited repair capability and the natural history of neurodegenerative diseases is not significantly modified by current therapies. Thus, the possible use of cell therapy has generated new expectations. However, the idea of simply replacing cells in order to substitute lost neurons or restoring a functionally competent myelin sheath and prevent neurodegeneration is wholly simplistic in view of the complex pathology of these diseases. The very poor homing and engrafting capability of transplanted cells has dampened the exciting expectations aroused by the capability of embryonic and adult somatic stem cells to differentiate into many different cell types. Problems such as the route of cell delivery, choice of administration timing, source and type of cells, differentiation degree, are all topics that have raised a number of unsolved questions. As an alternative to cell transplant, strategies aimed at improving the self-repair capability and/or neuroprotection through endogenous stem and precursor cells are currently under active investigation, also in view of safety issues. This short review deals with the latter approach, focusing on multiple sclerosis (MS), i.e. the most diffuse demyelinating disease of the central nervous system (CNS), and on the critical role played by thyroid hormones (THs) in developmental myelination and thus, possibly, in remyelination.

\section{MS: a puzzling disease in which myelin repair fails}

MS is an inflammatory demyelinating disease of the CNS with unknown aetiology, which progresses over decades, ultimately leading to permanent motor disabilities, cognitive and affective disorders (Compston $\&$ Coles 2002). It is the most frequent non-traumatic disabling neurological disease among young adults, with 12000 new diagnoses per year in the United States alone (Hirtz et al. 2007).

Different pathogenic events involving many cell types occur in the course of the disease. According to the classical view, inflammation and immune attack due to 
CNS invasion by peripheral Th1 lymphocytes are preeminent in the early phase of the disease; then demyelination and oligodendrocyte (OL) death prevails, leading to the lesion of the myelin sheaths and the appearance of multiple areas of demyelination widespread in the white and grey matters of the entire CNS. It has been also proposed that the early apoptotic death of OLs triggers microglial activation, with Th1 invasion as a secondary event (Barnett \& Prineas 2004, Barnett \& Sutton 2006). In any case, axonal pathology and neuron death have been recognized as major early events in the chronology of disabilities, correlating with both permanent disabilities and brain atrophy in advanced MS (Lassmann et al. 2007). Several pathogenic processes, such as inflammation, immune reaction, demyelination, OL death, axonal damage and neuron death, follow each other and overlap over the long course of the disease, all providing possible targets for therapeutic intervention. Indeed, several drug combinations are under active investigation as potential disease-modifying therapies (Lopez-Diego \& Weiner 2008).

Myelin repair is possible and may be effective also in terms of functional outcome, as it is the only truly competent repair mechanism operating in the mature CNS (Miller \& Mi 2007, Franklin \& Ffrench-Constant 2008, McTigue \& Tripathi 2008). This capability is largely guaranteed by the presence of a relatively recently described cell population in the CNS, which is identified by the presence of the membraneassociated chondroitin sulphate proteoglycan (NG2) and the $\alpha$ receptor for platelet-derived growth factor $(\mathrm{PDGF} \alpha \mathrm{R})$. These cells, which are not astrocytes, OLs or microglial cells, were originally identified as oligodendrocyte precursor cells (OPCs; Nishiyama et al. 1999, Dawson et al. 2000). OPCs are generated during development (de Castro \& Bribián 2005) and migrate over the entire CNS during late development, so that they are disseminated in the white and grey matter of the mature CNS, where they account for $5-8 \%$ of the total cell population (Levine et al. 2001). These cells have the remarkable capability of proliferating and migrating in the case of injury, and also of being able to differentiate into mature myelinating OLs (Baracskay et al. 2007). Moreover, new OPCs might be also generated by precursor cells, which are located in tissue niches in the mature CNS, including the subventricular zone (SVZ; Komitova et al. 2009) and the vascular niche (Arai \& Lo 2009). The SVZ is the largest germinative zone in the adult brain, which contains a well-characterized stem cell niche. While most studies highlight the neurogenic potential of progenitors, recent data indicate that SVZ cells become reactivated in response to different pathological cues, such as trauma, ischaemia, neurodegeneration, inflammation and demyelination. A severe desegregation of the niche, with enhanced proliferation and recruitment of progenitors into myelin lesions, has been demonstrated in experimental models of demyelination in rodents (Calzà et al. 1998a,b, Picard-Riera et al. 2002) and in MS (Nait-Oumesmar et al. 2007). Inflammation seems to be critical for activation of OPCs and progenitors and, ultimately, for successful myelin repair (Calzà et al. 2005, McQualter \& Bernard 2007). Remyelination is observed in areas of active inflammation in MS (Foote \& Blakemore 2005, Setzu et al. 2006), whereas it is impaired in mice lacking proinflammatory cytokines (Mason et al. 2001) or in the case of macrophage depletion (Kotter et al. 2005, Schonberg et al. 2007). At the same time, as a Janus phenomenon, chronic inflammation is detrimental in many pathological conditions leading to excitoxic lesion and altered redox balance (Sanders \& De Keyser 2007), and also impairs the capability of progenitors to generate new OLs (Pluchino et al. 2008).

In spite of the fact that a significant number of OPCs also newly generated from the SVZ are present and proliferate in early lesions in MS (Wolswijk 2002, Wilson et al. 2006), for some unknown reason OPC differentiation into myelinating OLs is blocked (Kuhlmann et al. 2008) and remyelination progressively fails in MS. The inefficiency or failure of myelin-forming OLs to remyelinate axons and preserve axonal integrity remains a major impediment of the repair of MS lesions and the factor principally responsible for axonal and neuronal degeneration, leading to chronic disability and brain and spinal cord atrophy. The reason for incompetent myelin repair in MS is still obscure (Miller \& Mi 2007, Rodriguez 2007, Dubois-Dalcq et al. 2008). Successful remyelination requires an orchestrated interplay among OPCs, extracellular matrix and axons. OPCs need to be appropriate in number, in the right position and prone to differentiate into mature OLs; the extracellular matrix, which provides the tissue architecture, has to properly regulate intercellular communication and cellular migration; axons have to provide appropriate membrane and soluble signals to OPCs (Camara \& ffrench-Constant 2007, Simons \& Trotter 2007). Moreover, other cellular and molecular players, including ependymal, endothelial, peripheral inflammatory cells, microglia, astrocytes, hormones, growth factors, etc. are in the arena of the 'battle between destruction and repair' in MS (McQualter \& Bernard 2007, Rodriguez 2007).

\section{Cell therapy to repair lesions in MS: in search of a rationale}

Autologous hematopoietic cell transplantation has been proposed for immune modulation/ablation in MS. Clinical trials have been completed and others 
are in progress. This type of cell therapy is not considered in this review. Stem cell transplantation has been also proposed to replace lost OLs also in MS, and tested in different rodent models of demyelination. Different cell types were used, deriving from syngenic, allogenic or xenogenic donors, including embryonic stem cells and adult somatic cells. Adult somatic stem cells, such as neural, hematopoietic and mesenchymal stem cell, but also other cell types, such as olfactory ensheathing cells, Schwann cells and differentiated OLs have been proposed (Lindvall \& Kokaia 2006, Aharonowiz et al. 2008, Chandran et al. 2008, Duncan 2008, Duncan et al. 2008, Einstein \& Ben-Hur 2008, Hommes 2008, Karussis \& Kassis 2008, Kulbatski et al. 2008, Payne et al. 2008, Sher et al. 2008, Yang et al. 2009). Also, more recently, autologous induced pluripotent stem cells appeared on the scene (Abeliovich \& Doege 2009).

In view of the fact that multifocal lesions in MS spread from the spinal cord to the optic nerve, the first issue to address was the route of administration in order to allow cells to penetrate the blood-brain barrier and reach the lesion sites. Intracerebroventricular and multiple intraparenchymal injections were used, but also i.v. peripheral administration, since inflammation renders the blood-brain barrier permeable in defined timewindows during the disease (Muller et al. 2005). Even if it is accepted that donor cells migrate preferentially to the site of tissue injury also after i.v. system administration, currently available data suggest that only a small percentage of systemically administered cells migrate in the CNS and few of them differentiate into myelinating cells (Pluchino et al. 2003).

This is largely due to the intrinsic properties of mature nervous tissue. In spite of the considerable structural and functional plasticity required to guarantee the normal functioning of the CNS, the possibility of structural rewriting after lesions also involving exogenous cells is extremely limited due to the intrinsic properties of cellular players and, probably even more important, due to the non-permissive adherent and soluble molecules that are present in the extracellular micro-environment. In the meantime, recent data regarding the beneficial effects of cell therapy in various animal models of demyelinating diseases indicate that transplanted or i.v injected stem cells possibly exert a positive effect through mechanisms other than cell replacement, such as attenuating deleterious inflammation, protecting remaining cells from degeneration, providing trophic or 'chaperone' support to the injured tissue and enhancing endogenous recovery processes (Pluchino et al. 2005, Einstein et al. 2007, Rosser et al. 2007).

At the same time, another obvious therapeutic approach is the attempt to improve myelin selfrepair capability by unblocking OPCs and pushing them toward becoming mature myelinating OLs (Dubois-Dalcq et al. 2005). They are directed toward antagonizing myelin inhibiting factors, such as LINGO (Rudick et al. 2008) or boosting promoting factors, such as THs.

\section{Embryology offers precious advice for myelin repair strategies based on endogenous stem and precursor cells}

Cellular and molecular events in successful myelin repair in adult CNS derive from the recapitulation of developmental myelination and lead to the synthesis of new myelin to ensheathe naked axons (Miller \& Mi 2007). Molecular, cellular and morphogenic processes during myelination require a spatially, temporally and quantitatively orchestrated sequence of genetically and epigenetically driven events, which also includes exposure to hormones and vitamins. THs play a key role in the development in all animal species and are crucial in early brain development, when proliferation and migration are predominant, and in later stages, also postnatally, when the maturation of different cell types, initiation of axonal and dendritic growth, myelination and synapse formation take place (Oppenheimer \& Schwartz 1997, Koibuchi \& Chin 2000, Howdeshell 2002, Koenig \& Neto 2002, Boelaert \& Franklyn 2005).

\section{TH and CNS}

Thyroxine $\left(\mathrm{T}_{4}\right)$ is the principal product of the thyroid gland and the most abundant circulating $\mathrm{TH}$; however, 3,3',5-triiodothyronine $\left(T_{3}\right)$ is the active form (Fig. 1). Transthyretin, synthesized by the choroid plexuses $(\mathrm{CP})$, has an important role in transporting $\mathrm{T}_{4}$ from blood to cerebrospinal fluid and to the brain (Chanoine et al. 1992, Chen et al. 2006, Kassem et al. 2006), where all cell types are TH-sensitive. Because of the lipophilic nature of $\mathrm{TH}$, it was thought that it traversed the plasma membrane by simple diffusion. However, in the past decade, membrane transport systems for TH have been demonstrated, i.e. organic anion transporters and amino acid transporters, among which MCT8 is strongly expressed in the CP, capillary endothelial cells and selected neuronal populations (Jansen et al. 2005, Taylor \& Ritchie 2007, Heuer \& Visser 2009). The biological activity of TH on target cells is determined by intracellular $\mathrm{T}_{3}$ concentration, which is dependent on the level of circulating $\mathrm{T}_{4}$ and $\mathrm{T}_{3}$, the presence of transporters on the plasma membrane and the activity of tissue specific deiodinases (Ds). Three distinct tissue-specific Ds have been identified (Gereben et al. 2008): D2 is the active isoform in the brain, converting $\mathrm{T}_{4}$ into $\mathrm{T}_{3}$, whereas $\mathrm{D} 3$ converts $\mathrm{T}_{3}$ into the inactive $\mathrm{rT}_{3}$. Most classic $\mathrm{TH}$ actions are 


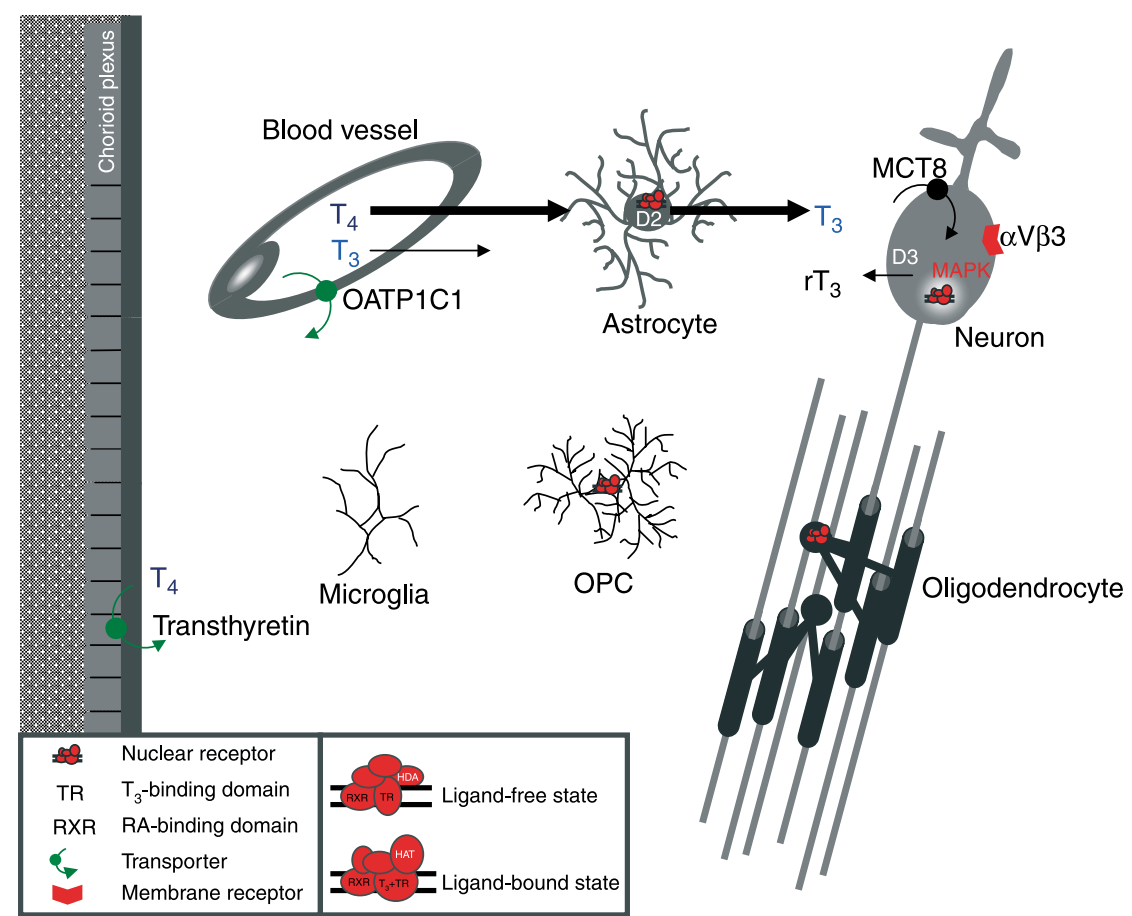

Figure 1 The cartoon summarizes the molecular and cellular players that guarantee a proper thyroid hormone signalling in the central nervous systems. $\alpha \mathrm{V} \beta 3$, integrin $\alpha \mathrm{V} \beta 3$; D2, type 2 deiodinase; D3, type 3 deiodinase; HAT, histone transacetylase activity;

MAPK, mitogen-activated protein (MAP) kinases; MCT8, monocarboxylate transporter 8; OATP1C1, organic anion transporting polypeptide 1C1; OPC, oligodendrocyte precursor cell; $\mathrm{rT}_{3}, 3,3^{\prime}, 5^{\prime}$-triiodothyronine; $\mathrm{RXR}$, retinoid $\mathrm{X}$ receptor; $\mathrm{T}_{3}, 3,5,3^{\prime}$-triiodothyronine; $\mathrm{T}_{4}$, thyroxine; TR, nuclear thyroid hormone receptor.

genomically mediated by $\mathrm{T}_{3}$ binding to nuclear receptors (TRs), which belong to the nuclear receptor superfamily (Yen 2001). TR $\alpha$ and TR $\beta$ genes encode for TRs. Alternative splicing of $\mathrm{TR} \alpha$ mRNA gives rise to $\mathrm{TR} \alpha 1$ and $\mathrm{TR} \alpha 2$, and the expression of the alternative DNA strand yields Ref-Erb-A $\alpha(\mathrm{A} \alpha 1, \mathrm{~A} \alpha 2)$, but neither $\mathrm{TR} \alpha 2$ nor Ref-Erb-A binds $\mathrm{T}_{3}$. Likewise, the alternative activation of promoters in the case of TR $\beta$ mRNA yields TR $\beta 1$, TR $\beta 2$ and TR $\beta 3$. More recently, two additional rat TR $\beta$ isoforms, TR $\beta 3$ and TR $\Delta \beta 3$, have been cloned (Williams 2000). The various TR isoforms are expressed in temporospatial-specific patterns during development and in distinct ratios in adult tissues and different cell types, suggesting that TR subtypes and isoforms play different roles in cell proliferation, differentiation, growth and maturation (Forrest et al. 1990, 1991, Puymirat et al. 1992, Sarlieve et al. 2004, Lemkine $e t$ al. 2005; Fig. 2). TRs have a central DNA-binding domain containing two 'zinc fingers' and a carboxy-terminal ligand-binding domain (LBD) as well as a domain coupling with another $T_{3}$ receptor or other nuclear receptors (e.g. retinoic acid $\mathrm{X}$ receptor) to form dimers. In most cases, interaction between the $T_{3}$ and its receptor prompts the binding of accessory protein cofactors that either activate or repress a specific gene's transcription. Acting as transcription factors, TRs play a vital role during embryonic development and metamorphosis, regulating cell cycle, cell growth and maturation (Calzà et al. 2000, Bassett et al. 2003). Expression of gene batteries is directly or indirectly regulated by TR in the brain and peripheral tissues (Dong et al. 2009). They include transcription factors, intracellular signalling molecules, hormones, such as GH and thyrotrophin-releasing hormone, cell-specific genes, such as the cerebellar Purkinje cell protein-2 and OL-specific genes (Calzà et al. 1997, Bernal et al. 2003).

Finally, a plasma membrane receptor site for $\mathrm{TH}$ on integrin $\alpha \mathrm{V} \beta 3$, which is linked by signal-transducing mitogen-activated protein kinase to mitogen-activated protein kinase-mediated intranuclear events, has been identified, opening up a completely new perspective for TH's role in architectural sculpture and tissue and organ maintenance (Calzà et al. 1997, Davis et al. 2005, Visser et al. 2008).

\section{TH and CNS myelination}

Myelination is a TH-dependent process (Bernal 2002, 2007, Zoeller \& Rovet 2004, Darras 2008). Studies in genetically modified animals (Baas et al. 2002, O'Shea \& 


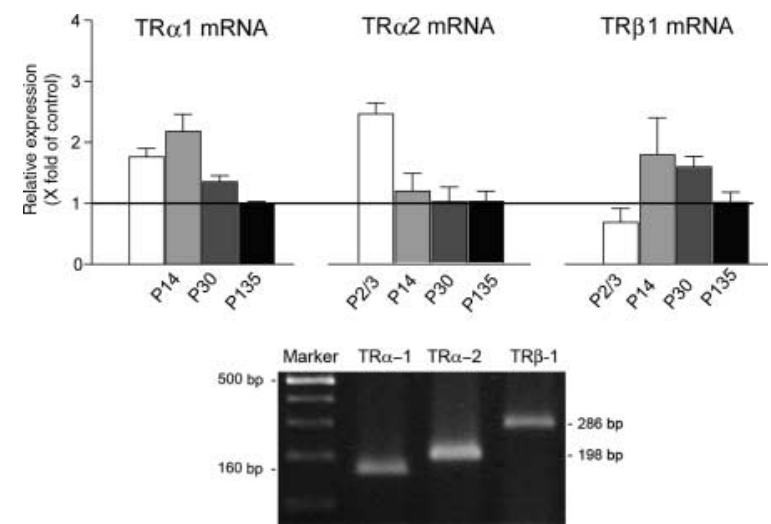

Figure 2 The expression of the different thyroid hormone receptor isoforms is temporally and spatially regulated in the CNS. The graph illustrates the expression of $\operatorname{TR} \alpha 1, \operatorname{TR} \alpha 2, \operatorname{TR} \beta 1$ in the cerebellum at post-natal days $2 / 3,14,30$ and 135 in the cerebellum of rats, as measured by real-time PCR, in which the expression level observed in adult rats (P135) is 1 .

The expression of $\alpha$ isoforms is higher in early post-natal age, whereas $\beta 1$ increases post-natally.

Williams 2002), including analysis of myelination in hypothyroid and hyperthyroid animals (Jagannathan et al. 1998, Obregon et al. 2007), have provided abundant evidence that $\mathrm{TH}$ plays an important part in regulating OL lineage and maturation in vivo. THs induce more OLs to form from multipotent neural stem cells (Rogister et al. 1999, Fernández et al. 2004b) and regulate several stages of OL development and maturation (Baas et al. 1997). Early in development, TH functions as an instructive agent, triggering OPCs (O-2A cell) cell cycle exit in close cooperation with platelet-derived growth factor (PDGF; Durand et al. 1997, Durand \& Raff 2000, Lu et al. 2008). According to the hypothesis developed by Raff's group for OL generation and maturation (Durand \& Raff 2000, Raff 2006) and further confirmed by other groups for different cell types (Papaioannou et al. 2007, Tsui et al. 2008), $\mathrm{T}_{3}$ is a major component of the molecular machinery that regulates OPC proliferation and differentiation through a mitogen-dependent intrinsic cell timer. When OPCs proliferate, they become sensitive to $\mathrm{T}_{3}$ after eight cell divisions (or corresponding time), probably because of a cell cycle-dependent expression of TRs (Maruvada et al. 2004). $\mathrm{T}_{3}$ stops cell division leading to terminal differentiation at appropriate times. More generally, $\mathrm{T}_{3}$ seems to be part of the complex timing molecular system that regulates fundamental cell activities, including cell cycle, in view of cellular programming and micro-environmental signals (Furlow \& Neff 2006; Fig. 3).

The TR isoform involved in proliferation arrest is still disputed: the $\beta 1$ isoform increases parallel to p27 during OL differentiation (Gao et al. 1998), but transfection experiments in mouse fibroblast have indicated that TR $\alpha$ but not TR $\beta$ causes the drastic arrest of proliferation (Sarlieve et al. 2004). A cell cycledependent balance among the different TR isoforms could regulate the differential hormonal sensitivity and thus the transcriptional response to $T_{3}$ in the different phases of the cell cycle (Maruvada et al. 2004). This is true not only during development, but also in mature CNS. TR $\alpha$ expression seems to decline as soon as OPCs progress toward myelinating OLs, whereas TR $\beta 1$ seems to be associated with terminal maturation (Sarlieve $e t$ al. 2004). Finally, THs stimulate the morphological and functional maturation of OLs by stimulating the expression of various genes, such as the myelin-OL glycoprotein, myelin basic protein (MBP) and glutamine synthase (Rodriguez-Pena 1999, Baumann \& Pham-Dinh 2001).

\section{TH and CNS remyelination}

In view of the key role of $\mathrm{TH}$ in developmental myelination, and since successful remyelination is a recapitulation of developmental myelination (Miller \& Mi 2007), an appropriate TH drive should be critical also for remyelination in MS. Thus, we have extensively explored the use of THs to favour oligodendroglial lineage and maturation from endogenous precursors in order ultimately to improve remyelination in animal models of MS. Our approach attempts to combine cellular and molecular notions regarding the role of $\mathrm{TH}$ in oligodendroglial commitment from undifferentiated precursors and myelination during development, and an accurate knowledge and use of the animal models of MS (Calzà et al. 2005). In particular, we focused on two facts that seem to be critical in remyelination failure in MS. First, there is an extensive proliferation of OPCs (and progenitors in the SVZ) during the acute phase of experimental allergic encephalomyelitis (EAE) and in fresh MS plaques. Second, proliferating OPCs are unable to withdraw cell cycle and progress toward mature myelinating OLs; this differentiation block has been indicated as a cause of remyelination failure (Kuhlmann et al. 2008).

This altered cell regulation is possibly related to the exposure to a cytokine mix due to early inflammation. Exposure to cytokine mix including interferon- $\gamma$ $(\mathrm{IFN}-\gamma)$, tumour necrosis factor- $\alpha$ (TNF- $\alpha)$ and interleukin-1 $\beta$, which are those found in the inflammatory phase in EAE and MS (Frohman et al. 2006), increases the number of OPCs, blocking their differentiation (Kuhlmann et al. 2008). Moreover, exposure of OPCs to IFN- $\gamma$ prevents differentiation and cell cycle withdrawal, and significantly attenuates MBP expression (Chew et al. 2005). Prolonged exposure to proinflammatory cytokines further impairs the capability of progenitors to generate OPCs (Pluchino et al. 2008), thus contributing to OPC depletion in chronic lesions. 

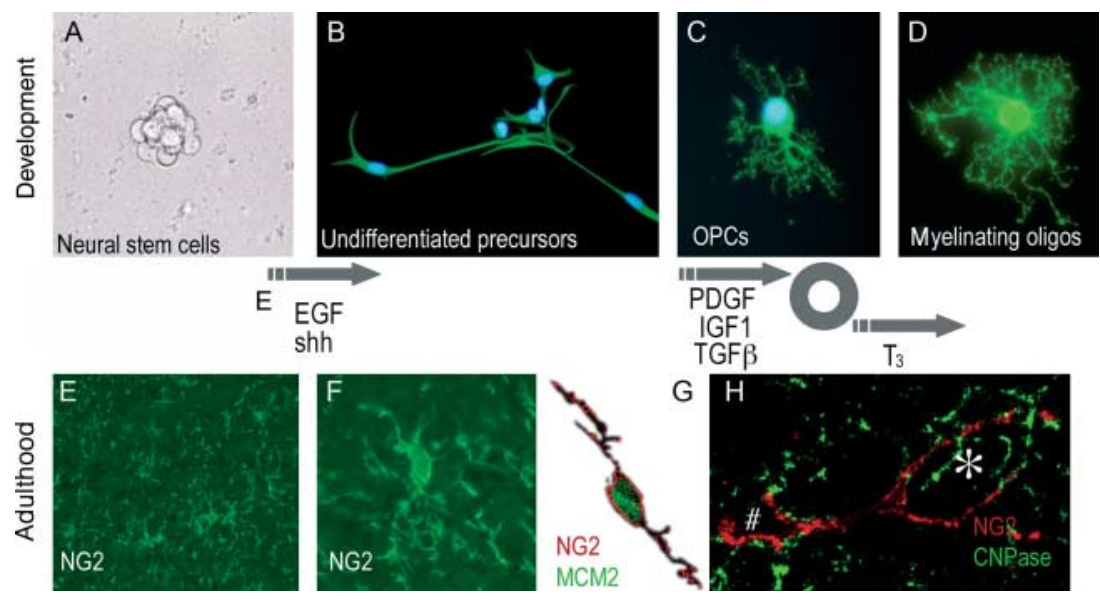

Figure 3 Oligodendrocyte generation in vitro $(A-D)$ and in vivo $(E-H)$. Mature oligodendrocytes may be derived from neural stem cells obtained from the subventricular zone of adult mammals. When cultured in the presence of mitogens, neural precursors proliferate in clustered aggregates (A); as soon as mitogens are withdrawn, cells spontaneously differentiate, first forming undifferentiated precursors (B: nestin-positive), then the main cell types of the CNS. The transition from OPCs to OLs requires a complex molecular machinery, including intrinsic and extrinsic elements (see text). OPCs are identified by NG2-positivity (C) and mature OLs by CNPase-immunoreactivity and both show a competent morphology of the respective phenotype. OPCs can also be identified in tissue section by NG2-positivity, in both the grey and the white matter ( $E$ and F). When observed at higher magnifications, these cells appear small, with finely branched short elongations $(F)$; when activated, they withdraw the elongation and express proliferationassociated nuclear antigen, i.e. MCM2 (G). During remyelination, NG2 cells envelop CNPase-positive myelin sheaths, as illustrated by confocal microscopy $(\mathrm{H}) .{ }^{*}$, myelinated axon; \#, vessel. CNPase, $2^{\prime}, 3^{\prime}$-cyclic nucleotide $3^{\prime}$-phosphodiesterase; EGF, epidermal growth factor IGF1; insulin-like growth factor 1; MCM2, minichromosome maintenance complex component 2; NG2, chondroitin sulphate proteoglycan; OCPs, oligodenrocyte precursor cells; PDGF(R $\alpha)$, platelet-derived growth factor (receptor alpha); shh, Sonic hedgehog; $T_{3}, 3,5,3^{\prime}$-triiodothyronine; TGF $\beta$, transforming growth factor $\beta$.

A proinflammatory cytokine mix could be also responsible for an inappropriate $\mathrm{TH}$-drive of OPC maturation. Indeed, one accepted concept is that $\mathrm{TH}$ action at cellular level (but also $\mathrm{T}_{3}$ serum level) is locally regulated by $\mathrm{D}$ activity and TR expression, and this is relatively independent of $\mathrm{TH}$ serum concentration (Bianco \& Kim 2006, Gereben et al. 2008, St Germain et al. 2009). In particular, D2 activation increases intracellular $\mathrm{T}_{3}$ concentration, and this saturates local TRs, significantly regulating transcription of $\mathrm{T}_{3}$-responsive genes (Gereben et al. 2008). The opposite effect is produced by D3 activation. Proinflammatory cytokines are able to alter Ds activity, thus leading to a decreased local $\mathrm{T}_{3}$ production and reduced $\mathrm{rT}_{3}$ degradation, a biochemical condition leading to local hypothyroidism (Papanicolau 2000). Proinflammatory cytokines also inhibit TR $\beta 1$ gene expression (Tauchmanovà et al. 2005, Kwakkel et al. 2007). A reduced $\mathrm{T}_{3}$ production by $\mathrm{D} 2$ inhibition or due to a dysregulation of TR expression triggered by interleukin $1 \beta$ and TNF $\alpha$ has been described in the hypothalamus (Boelen et al. 2004), hepatic cells (Boelen et al. 2006, Kwakkel et al. 2007) and pituitary cells (Baur et al. 2000).
Immune activation and brain injury itself decreases the activity of D2 (Fekete et al. 2004, Margaill et al. 2005). According to this hypothesis, a decrease in tissue availability of $\mathrm{T}_{3}$ or an impairment of nuclear receptors or $\mathrm{TH}$ transporter expression due to inflammation deprives OPCs of a key signal for cell cycle exit and maturation into myelinating OLs.

This could explain the beneficial effects of $\mathrm{TH}$ administration on the clinical and pathological evolution of EAE and cuprizone demyelination as observed by us and others. We have shown that TH administration improves EAE clinical course and the remyelination process in Lewis and Dark-Agouty rats and in the non-human primate Callithrix jacchus (marmoset), favouring remyelination and neuroprotection without resulting in hyperthyroidism (Calzà et al. 2002, 2005, Fernández et al. 2004a,b, Giardino et al. 2007). This effect occurs when $\mathrm{TH}$ is administered in the acute phase of the disease, when OPCs and progenitors proliferate actively (Calzà et al. 1998a,b). We found that TH treatment reduces the number of proliferating cells in SVZ and spinal cord, and favours OPC differentiation in EAE rats. The in vivo formation 
of new OLs has been tracked using different markers for OPC differentiation, such as oligodendroglial committed precursor (nestin and PSA-NCAM), A2B5 and PDGFR $\alpha$ as progenitor and pre-OL; O4 as pre-OL and immature OL; O4, NG2 and MBP as nonmyelinating and myelinating mature OL. TH treatment induces the onset of O4-positive cells and up-regulation of A2B5-IR and PDGFR $\alpha$ in EAE, but not in control animals. $T_{3}$ administration completely restores the capability to produce MBP (mRNA and protein), which reflects a mature stage of the OL and is impaired in EAE. Finally, myelin organization and sheath thickness are restored by $\mathrm{TH}$ treatment. Moreover, $\mathrm{T}_{3}$ also up-regulates mRNA expression of Olig1, which is one of the early genes expressed by neural stem cells during oligodendroglial lineage, thus suggesting that new OPCs are formed during EAE under the $\mathrm{T}_{3}$ drive. The clinical course of EAE rats and non-human primates is also positively affected, as indicated by the less severe relapse in treated animals.

Recently, the rationale proposed by us for improving myelin self-repair through stimulation of OPCs was successfully applied on cuprizone demyelination in rats and mice. In particular, Franco et al. (2008) showed that remyelination in the corpus callosum of $\mathrm{T}_{3}$-treated rats improved markedly when compared with salinetreated animals. In the white matter of saline-treated demyelinated animals, OLs decreased and OPCs increased and the SVZ showed an increase in early progenitor cell numbers, dispersion of OPCs and inhibition of Olig and Sonic hedgehog (Shh) expression compared to non-demyelinated animals. The changes triggered by demyelination were reversed after $\mathrm{T}_{3}$ administration, confirming that THs could be regulating the emergence of remyelinating OLs from the pool of proliferating cells residing in the SVZ. Harsan et al. (2008) analysed $\mathrm{T}_{3}$ effect on cuprizone demyelination in mice, using a combination of in vivo diffusion tensor magnetic resonance imaging (MRI) and histological analyses. $\mathrm{T}_{3}$ restored the normal diffusion tensor (DT)-MRI phenotype accompanied by an improvement of clinical signs and remyelination. $\mathrm{T}_{3}$ also increased the expression of $\mathrm{Shh}$ and the numbers of Olig2- and PSA-NCAM-positive precursors and proliferative cells.

The effect of exogenous administration of $\mathrm{TH}$ in regulating the demyelination/remyelination ratio in animal models of MS might also involve other cell types, as almost all animal cells are sensitive to TH. The immune cells contain $\mathrm{T}_{3}$ (Pállinger \& Csaba 2008), supporting the view of a complex and still poorly understood interaction between $\mathrm{TH}$ and immune function (Klecha et al. 2006). TH also regulates the expression of cytoskeleton protein during axon growth and regeneration (Schenker et al. 2002), thus indirectly modulating the axon-OL interplay that provides for proper white matter development and organization (Berbel et al. 1994, Guadaño Ferraz et al. 1994). Finally, astrocytes, which are critical players in the complex scenario of inflammatory/demyelinating disease, are the cells that produce $\mathrm{T}_{3}$ in the CNS and, at the same time, provide a target for $\mathrm{T}_{3}$ action. TH regulates several aspects of astrocyte differentiation and maturation, including the production of extracellular matrix proteins and growth factors, and thus controls neuronal growth and neuritogenesis (Trentin 2006). $\mathrm{T}_{3}$ alters the expression and organization of several extracellular matrix proteins including laminin, fibronectin and syndecan, which are produced by astrocytes (Mendes-de-Aguiar et al. 2008). Since the extracellular matrix 3D organization is severely altered in EAE and MS (Maier et al. 2005), this could also be a target for $\mathrm{T}_{3}$ effects.

In conclusion, endogenous stem and precursor cells could represent an important resource for cell therapies applied to myelin repair. To successfully pursue the attempt to involve these cell populations in self-repair, a greater knowledge of the disease's progression as well as of endogenous stem and precursor cell biology is needed.

\section{Declaration of interest}

The authors declare that there is no conflict of interest that would prejudice the impartiality of this scientific work.

\section{Funding}

This work was supported by the Emilia-Romagna Region; Fondazione IRET, Ozzano Emilia; Centro di Fisiopatologia del Sistema Nervoso, Modena.

\section{Acknowledgements}

The authors wish to thank all present and past collaborators who contributed to these studies: Marco Alessandri, Luigi Aloe, Chen BinLai, Giovanna Del Vecchio, Nadia DeSordi, Giulia D'Intino, Alessandro Giuliani, Marco Gusciglio, Giulia Izzo, Luca Lorenzini, Michela Paradisi, Stefania Pirondi, Sandra Sivilia.

\section{References}

Abeliovich A \& Doege CA 2009 Reprogramming therapeutics: iPS cell prospects for neurodegenerative disease. Neuron 61 337-339.

Aharonowiz M, Einstein O, Fainstein N, Lassmann H, Reubinoff B \& Ben-Hur T 2008 Neuroprotective effect of transplanted human embryonic stem cell-derived neural precursors in an animal model of multiple sclerosis. PLoS ONE 3 e3145.

Arai K \& Lo EH 2009 An oligovascular niche: cerebral endothelial cells promote the survival and proliferation of oligodendrocyte precursor cells. Journal of Neuroscience 29 4351-4355. 
Baas D, Bourbeau D, Sarlieve LL, Ittel ME, Dussault JH \& Puymirat J 1997 Oligodendrocyte maturation and progenitor cell proliferation are independently regulated by thyroid hormone. Glia 19 324-332.

Baas D, Legrand C, Samarut J \& Flamant F 2002 Persistence of oligodendrocyte precursor cells and altered myelination in optic nerve associated to retina degeneration in mice devoid of all thyroid hormone receptors. PNAS 99 2907-2911.

Baracskay KL, Kidd GJ, Miller RH \& Trapp BD 2007 NG2-positive cells generate A2B5-positive oligodendrocyte precursor cells. Glia $\mathbf{5 5}$ $1001-1010$.

Barnett MH \& Prineas JW 2004 Relapsing and remitting multiple sclerosis: pathology of the newly forming lesion. Annals of Neurology 55 458-468.

Barnett MH \& Sutton I 2006 The pathology of multiple sclerosis: a paradigm shift. Current Opinion in Neurology 19 242-247.

Bassett JH, Harvey CB \& Williams GR 2003 Mechanisms of thyroid hormone receptor-specific nuclear and extra nuclear actions. Molecular and Cellular Endocrinology 213 1-11.

Baumann N \& Pham-Dinh D 2001 Biology of oligodendrocyte and myelin in the mammalian central nervous system. Physiological Reviews 81 871-927.

Baur A, Bauer K, Jarry H \& Köhrle J 2000 Effects of proinflammatory cytokines on anterior pituitary $5^{\prime}$-deiodinase type I and type II. Journal of Endocrinology 167 505-515.

Berbel P, Guadaño-Ferraz A, Angulo A \& Ramón Cerezo J 1994 Role of thyroid hormones in the maturation of interhemispheric connections in rats. Behavioural Brain Research 64 9-14.

Bernal J 2002 Action of thyroid hormone in brain. Journal of Endocrinological Investigation 25 268-288.

Bernal J 2007 Thyroid hormone receptors in brain development and function. Nature Clinical Practice. Endocrinology and Metabolism 3 249-259.

Bernal J, Guadaño-Ferraz A \& Morte B 2003 Perspectives in the study of thyroid hormone action on brain development and function. Thyroid 13 1005-1012.

Bianco AC \& Kim BW 2006 Deiodinases: implications of the local control of thyroid hormone action. Journal of Clinical Investigation 16 2571-2579.

Boelaert K \& Franklyn JA 2005 Thyroid hormone in health and disease. Journal of Endocrinology 187 1-15.

Boelen A, Kwakkel J, Platvoet-ter Schiphorst M, Mentrup B, Baur A, Koehrle J \& Wiersinga WM 2004 Interleukin-18, a proinflammatory cytokine, contributes to the pathogenesis of non-thyroidal illness mainly via the central part of the hypothalamus-pituitary-thyroid axis. European Journal of Endocrinology 151 497-502.

Boelen A, Kwakkel J, Wiersinga WM \& Fliers E 2006 Chronic local inflammation in mice results in decreased TRH and type 3 deiodinase mRNA expression in the hypothalamic paraventricular nucleus independently of diminished food intake. Journal of Endocrinology 191 707-714.

Calzà L, Aloe L \& Giardino L 1997 Thyroid hormone-induced plasticity in the adult rat brain. Brain Research Bulletin 44 549-557.

Calzà L, Giardino L, Pozza M, Bettelli C, Micera A \& Aloe L 1998a Proliferation and phenotype regulation in the subventricular zone during experimental allergic encephalomyelitis: in vivo evidence of a role for nerve growth factor. PNAS 95 3209-3214.

Calzà L, Giardino L \& Hokfelt T 1998b Thyroid hormone-dependent regulation of galanin synthesis in neurons and glial cells after colchicines administration. Neuroendocrinology 68 428-436.

Calzà L, Forrest D, Vennstrom B \& Hokfelt T 2000 Expression of peptides and other neurochemical markers in hypothalamus and olfactory bulb of mice devoid of all known thyroid hormone receptors. Neuroscience 101 1001-1012.

Calzà L, Fernández M, Giuliani A, Aloe L \& Giardino L 2002 Thyroid hormone activates oligodendrocyte precursors and increases a myelin-forming protein and NGF content in the spinal cord during experimental allergic encephalomyelitis. PNAS 99 3258-3263.
Calzà L, Fernandez M, Giuliani A, Pirondi S, D’Intino G, Manservigi M, DeSordi N \& Giardino L 2004 Stem cells and nervous tissue repair: from in vitro to in vivo. In NGF and Related Molecules in Health and Disease, Progress in Brain Research, vol 146, pp 75-91. Eds L Aloe \& L Calzà. Amsterdam: Elsevier.

Calzà L, Fernandez M, Giuliani A, D'Intino G, Pirondi S, Sivilia S, Paradisi M, De Sordi N \& Giardino L 2005 Thyroid hormone and remyelination in adult central nervous system: a lesson from an inflammatory-demyelinating disease. Brain Research Reviews 48 339-346.

Camara J \& ffrench-Constant C 2007 Lesson from oligodendrocyte biology on promoting repair in multiple sclerosis. Journal of Neurology 254 I15-I22.

de Castro F \& Bribian A 2005 The molecular orchestra of the migration of oligodendrocyte precursors during development. Brain Research. Brain Research Reviews 49 227-241.

Chandran S, Hunt D, Joannides A, Zhao C, Compston A \& Franklin RJ 2008 Myelin repair: the role of stem and precursor cells in multiple sclerosis. Philosophical Transactions of the Royal Society of London. Series B, Biological Sciences 363 171-183.

Chanoine JP, Alex S, Fang SL, Stone S, Leonard JL, Körhle J \& Braverman LE 1992 Role of transthyretin in the transport of thyroxine from the blood to the choroid plexus, the cerebrospinal fluid, and the brain. Endocrinology 130 933-938.

Chen RL, Kassem NA \& Preston JE 2006 Dose-dependent transthyretin inhibition of $\mathrm{T}_{4}$ uptake from cerebrospinal fluid in sheep. Neuroscience Letters 396 7-11.

Chew LJ, King WC, Kennedy A \& Gallo V 2005 Interferon- $\gamma$ inhibits cell cycle exit in differentiating oligodendrocyte progenitor cells. Glia 52 127-143.

Compston A \& Coles A 2002 Multiple sclerosis. Lancet 359 1221-1231.

Darras VM 2008 Endocrine disrupting polyhalogenated organic pollutants interfere with thyroid hormone signalling in the developing brain. Cerebellum 7 26-37.

Davis PJ, Davis FB \& Cody V 2005 Membrane receptors mediating thyroid hormone action. Trends in Endocrinology and Metabolism 16 429-435.

Dawson MR, Levine JM \& Reynolds R 2000 NG2-expressing cells in the central nervous system: are they oligodendroglial progenitors? Journal of Neuroscience Research 61 471-479.

Dong H, Yauk CL, Rowan-Carroll A, You SH, Zoeller RT, Lambert I \& Wade MG 2009 Identification of thyroid hormone receptor binding sites and target genes using ChIP-on-chip in developing mouse cerebellum. PLoS ONE 4 e4610.

Dubois-Dalcq M, Ffrench-Constant C \& Franklin RJ 2005 Enhancing central nervous system remyelination in multiple sclerosis. Neuron 48 9-12.

Dubois-Dalcq M, Williams A, Stadelmann C, Stankoff B, Zalc B \& Lubetzki C 2008 From fish to man: understanding endogenous remyelination in central nervous system demyelinating diseases. Brain 131 1686-1700.

Duncan ID 2008 Replacing cells in multiple sclerosis. Journal of the Neurological Sciences 265 89-92.

Duncan ID, Goldman S, Macklin WB, Rao M, Weiner LP \& Reingold SC 2008 Stem cell therapy in multiple sclerosis: promise and controversy. Multiple Sclerosis 14 541-546.

Durand B \& Raff V 2000 A cell-intrinsic timer that operates during oligodendrocyte development. BioEssays 22 64-71.

Durand B, Gao FB \& Raff M 1997 Accumulation of the cyclindependent kinase inhibitor p27/kip1 and the timing of oligodendrocyte differentiation. EMBO Journal 16 306-317.

Einstein O \& Ben-Hur T 2008 The changing face of neural stem cell therapy in neurologic diseases. Archives of Neurology 65 452-456.

Einstein O, Fainstein N, Vaknin I, Mizrachi-Kol R, Reihartz E, Grigoriadis N, Lavon I, Baniyash M, Lassmann H \& Ben-Hur T 2007 
Neural precursors attenuate autoimmune encephalomyelitis by peripheral immunosuppression. Annals of Neurology $\mathbf{6 1}$ 209-218.

Fekete C, Marks DL, Sarkar S, Emerson CH, Rand WM, Cone RD \& Lechan RM 2004 Lipopolysaccharide induces type 2 iodothyronine deiodinase in the mediobasal hypothalamus: implications for the nonthyroidal illness syndrome. Endocrinology 145 1649-1655.

Fernández M, Giuliani A, Pirondi S, D'Intino G, Giardino L, Aloe L, Levi-Montalcini R \& Calzà L 2004a Thyroid hormone administration enhances remyelination in chronic demyelinating inflammatory disease. PNAS 101 16363-16368.

Fernández M, Pirondi S, Manservigi M, Giardino L \& Calzà L 2004b Thyroid hormone participates in the regulation of neural stem cells and oligodendrocyte precursor cells in the central nervous system of adult rat. European Journal of Neuroscience 20 2059-2070.

Foote AK \& Blakemore WF 2005 Inflammation stimulates remyelination in areas of chronic demyelination. Brain 128 528-539.

Forrest D, Sjoberg M \& Vennstrom B 1990 Contrasting developmental and tissue-specific expression of $\alpha$ and $\beta$ thyroid hormone receptor genes. EMBO Journal 9 1519-1528.

Forrest D, Hallbook F, Persson H \& Vennstrom B 1991 Distinct functions for thyroid hormone receptors $\alpha$ and $\beta$ in brain development indicated by differential expression of receptor genes. EMBO Journal 10 269-275.

Franco PG, Silvestroff L, Soto EF \& Pasquini JM 2008 Thyroid hormones promote differentiation of oligodendrocyte progenitors cells and improve remyelination after cuprizone-induced demyelination. Experimental Neurology 212 458-467.

Franklin RJ \& Ffrench-Constant C 2008 Remyelination in the CNS: from biology to therapy. Nature Reviews. Neuroscience 9 839-855.

Frohman EM, Racke MK \& Raine CS 2006 Multiple sclerosis - the plaque and its pathogenesis. New England Journal of Medicine 354 942-955.

Furlow JD \& Neff ES 2006 A developmental switch induced by thyroid hormone: Xenopus laevis metamorphosis. Trends in Endocrinology and Metabolism 17 40-47.

Gao FB, Apperly J \& Raff V 1998 Cell-intrinsic timers and thyroid hormone regulate the probability of cell-cycle withdrawal and differentiation of oligodendrocyte precursor cells. Developmental Biology 197 54-66.

Gereben B, Zavacki AM, Ribich S, Kim BW, Huang SA, Simonides WS, Zeöld A \& Bianco AC 2008 Cellular and molecular basis of deiodinase-regulated thyroid hormone signaling. Endocrine Reviews 29 898-938.

St Germain DL, Galton VA \& Hernandez A 2009 Minireview: defining the roles of the iodothyronine deiodinases: current concepts and challenges. Endocrinology 150 1097-1107.

Giardino L, D'Intino G, Lorenzini L, Del Vecchio G, Perretta G, Tagioni A, Villoslada P \& Calzà L 2007 Thyroid hormone administration favours remyelination in experimental allergic encephalomyelitis in the non human primate marmoset (Callithrix jacchus) 37th meeting of the Society for Neuroscience 335.2.

Guadaño Ferraz A, Escobar del Rey F, Morreale de Escobar G, Innocenti GM \& Berbel P 1994 The development of the anterior commissure in normal and hypothyroid rats. Brain Research. Developmental Brain Research 81 293-308.

Harsan LA, Steibel J, Zaremba A, Agin A, Sapin R, Poulet P, Guignard B, Parizel N, Grucker D, Boehm N et al. 2008 Recovery from chronic demyelination by thyroid hormone therapy: myelinogenesis induction and assessment by diffusion tensor magnetic resonance imaging. Journal of Neuroscience 28 14189-14201.

Heuer H \& Visser TJ 2009 Minireview: pathophysiological importance of thyroid hormone transporters. Endocrinology $\mathbf{1 5 0}$ 1078-1083.

Hirtz D, Thurman DJ, Gwinn-Hardy K, Mohamed M, Chaudhuri AR \& Zalutsky R 2007 How common are the 'common' neurologic disorders? Neurology 68 326-337.
Hommes OR 2008 Can we pass from the experimental to the clinical phase in MS stem cell research? Journal of the Neurological Sciences $\mathbf{2 6 5}$ 136-139.

Howdeshell KL 2002 A model of the development of the brain as a construct of the thyroid system. Environmental Health Perspectives 110 337-348.

Jagannathan NR, Tandon N, Raghunathan P \& Kochupillai N 1998 Reversal of abnormalities of myelination by thyroxine therapy in congenital hypothyroidism: localized in vivo proto magnetic resonance spectroscopy (MRS) study. Developmental Brain Research 109 179-186.

Jansen J, Friesema EC, Milici C \& Visser TJ 2005 Thyroid hormone transporters in health and disease. Thyroid 15 57-68.

Karussis D \& Kassis I 2008 The potential use of stem cells in multiple sclerosis: an overview of the preclinical experience. Clinical Neurology and Neurosurgery 110 889-896.

Kassem NA, Deane R, Segal MB \& Preston JE 2006 Role of transthyretin in thyroxine transfer from cerebrospinal fluid to brain and choroid plexus. American Journal of Physiology. Regulatory, Integrative and Comparative Physiology 291 R1310-R1315.

Klecha AJ, Genaro AM, Gorelik G, Barreiro Arcos ML, Silberman DM, Schuman M, Garcia SI, Pirola C \& Cremaschi GA 2006 Integrative study of hypothalamus-pituitary-thyroid-immune system interaction: thyroid hormone-mediated modulation of lymphocyte activity through the protein kinase $\mathrm{C}$ signaling pathway. Journal of Endocrinology 189 45-55.

Koenig S \& Neto VM 2002 Thyroid hormone actions on neural cells. Cellular and Molecular Neurobiology 22 517-544.

Koibuchi N \& Chin WW 2000 Thyroid hormone action and brain development. Trends in Endocrinology and Metabolism 11 123-128.

Komitova M, Zhu X, Serwanski DR \& Nishiyama A 2009 NG2 cells are distinct from neurogenic cells in the postnatal mouse subventricular zone. Journal of Comparative Neurology 512 702-716.

Kotter MR, Zhao C, van Rooijen N \& Franklin RJ 2005 Macrophagedepletion induced impairment of experimental CNS remyelination is associated with a reduced oligodendrocyte progenitor cell response and altered growth factor expression. Neurobiological Disorders 18 166-175.

Kuhlmann T, Miron V, Cuo Q, Wegner C, Antel J \& Brück W 2008 Differentiation block of oligodendroglial progenitor cells as a cause for remyelination failure in chronic multiple sclerosis. Brain 131 $1749-1758$.

Kulbatski I, Mothe AJ, Parr AM, Kim H, Kang CE, Bozkurt G \& Tator CH 2008 Glial precursor cell transplantation therapy for neurotrauma and multiple sclerosis. Progress in Histochemistry and Cytochemistry 43 123-176.

Kwakkel J, Wiersinga WM \& Boelen A 2006 Differential involvement of nuclear factor- $\kappa \mathrm{B}$ and activator protein-1 pathways in the interleukin- $1 \beta$-mediated decrease of deiodinase type 1 and thyroid hormone receptor $\beta 1$ mRNA. Journal of Endocrinology 189 $37-44$.

Kwakkel J, Wiersinga WM \& Boelen A 2007 Interleukin-1 beta modulates endogenous thyroid hormone alpha gene transcription in liver cells. Journal of Endocrinology 194 257-265.

Lassmann H, Brück W \& Lucchinetti CF 2007 The immunopathology of multiple sclerosis: an overview. Brain Pathology 17 210-218.

Lemkine GF, Raj A, Alfama G, Turque N, Hassani Z, Alegria-Prévot O, Samarut J, Levi G \& Demeneix BA 2005 Adult neural stem cell cycling in vivo requires thyroid hormone and its $\alpha$ receptor. FASEB Journal 19 863-865.

Levine JM, Reynolds R \& Fawcett JW 2001 The oligodendrocyte precursor cell in health and disease. Trends in Neurosciences 24 39-47.

Lindvall O \& Kokaia Z 2006 Stem cells for the treatment of neurological disorders. Nature 441 1094-1096.

Lopez-Diego RS \& Weiner HL 2008 Novel therapeutic strategies for multiple sclerosis - a multifaceted adversary. Nature Reviews. Drug Discovery 7 909-925. 
Lu H-Z, Wang Y-X, Li Y, Fu S-L, Hang Q \& Lu P-H 2008 Proliferation and differentiation of oligodendrocyte progenitor cells induced from rat embryonic neural precursor cells followed by flow cytometry. Cytometry 73A 754-760.

Maier O, van der Heide T, van Dam AM, Baron W, de Vries H \& Hoekstra D 2005 Alteration of the extracellular matrix interferes with raft association of neurofascin in oligodendrocytes. Potential significance for multiple sclerosis? Molecular and Cellular Neurosciences 28 390-401.

Margaill I, Royer J, Lerouet D, Ramaugé M, Le Goascogne C, Li WW, Plotkine M, Pierre M \& Courtin F 2005 Induction of type 2 iodothyronine deiodinase in astrocytes after transient focal cerebral ischemia in the rat. Journal of Cerebral Blood Flow and Metabolism 25 468-476.

Maruvada P, Dmitrieva NI, East-Palmer J \& Yen PM 2004 Cell cycledependent expression of thyroid hormone receptor- $\beta$ is a mechanism for variable hormone sensitivity. Molecular Biology of the Cell 15 1895-1903.

Mason JL, Suzuki K, Chaplin DD \& Matsushima GK 2001 Interleukin$1 \beta$ promotes repair of the CNS. Journal of Neuroscience 21 7046-7052.

McQualter JL \& Bernard CC 2007 Multiple sclerosis: a battle between destruction and repair. Journal of Neurochemistry 100 295-306.

McTigue DM \& Tripathi RB 2008 The life, death, and replacement of oligodendrocytes in the adult CNS. Journal of Neurochemistry 107 $1-19$.

Mendes-de-Aguiar CB, Costa-Silva B, Alvarez-Silva M, Tasca CI \& Trentin AG 2008 Thyroid hormone mediates syndecan expression in rat neonatal cerebellum. Cellular and Molecular Neurobiology 28 795-801.

Miller RH \& Mi S 2007 Dissecting demyelination. Nature Neuroscience 10 1351-1354.

Muller DM, Pender MP \& Greer JM 2005 Blood-brain barrier disruption and lesion localisation in experimental autoimmune encephalomyelitis with predominant cerebellar and brainstem involvement. Journal of Neuroimmunology 160 162-169.

Nait-Oumesmar B, Picard-Riera N, Kerninon C, Decker L, Seilhean D, Höglinger GU, Hirsch EC, Reynolds R \& Baron-Van Evercooren A 2007 Activation of the subventricular zone in multiple sclerosis: evidence for early glial progenitors. PNAS 104 4694-4699.

Nishiyama A, Chang A \& Trapp BD 1999 NG2 + glial cells: a novel glial cell population in the adult brain. Journal of Neuropathology and Experimental Neurology 58 1113-1124.

Obregon MJ, Calvo RM, Del Rey FE \& de Escobar GM 2007 Ontogenesis of thyroid function and interactions with maternal function. Endocrine Development 10 86-98.

Oppenheimer JH \& Schwartz HL 1997 Molecular basis of thyroid hormone-dependent brain development. Endocrine Reviews 18 $462-475$.

O'Shea PJ \& Williams GR 2002 Insight into the physiological actions of thyroid hormone receptors from genetically modified mice. Journal of Endocrinology 175 553-570.

Pállinger E \& Csaba G 2008 A hormone map of human immune cells showing the presence of adrenocorticotropic hormone, triiodothyronine and endorphin in immunophenotyped white blood cells. Immunology 123 584-589.

Papaioannou M, Melle C \& Baniahmad A 2007 The coregulator Alien. Nuclear Receptor Signaling $\mathbf{5}$ e008.

Papanicolau DA 2000 Euthyroid sick syndrome and the role of cytokines. Reviews in Endocrine and Metabolic Disorders $143-48$.

Payne N, Siatskas C \& Bernard CC 2008 The promise of stem cell and regenerative therapies for multiple sclerosis. Journal of Autoimmunity 31 288-294.

Picard-Riera N, Decker L, Delarasse C, Goude K, Nait-Oumesmar B, Liblau R, Pham-Dinh D \& Evercooren AB 2002 Experimental autoimmune encephalomyelitis mobilizes neural progenitors from the subventricular zone to undergo oligodendrogenesis in adult mice. PNAS 99 13211-13216.
Pluchino S, Quattrini A, Brambilla E, Gritti A, Salani G, Dina G, Galli R, Del Carro U, Amadio S, Bergami A et al. 2003 Injection of adult neurospheres induces recovery in a chronic model of multiple sclerosis. Nature 422 688-694.

Pluchino S, Zanotti L, Rossi B, Brambilla E, Ottoboni L, Salani G, Martinello M, Cattalini A, Bergami A, Furlan R et al. 2005 Neurosphere-derived multipotent precursors promote neuroprotection by an immunomodulatory mechanism. Nature 436 266-271.

Pluchino S, Muzio L, Imitola J, Deleidi M, Alfaro-Cervello C, Salani G, Porcheri C, Brambilla E, Cavasinni F, Bergamaschi A et al. 2008 Persistent inflammation alters the function of the endogenous brain stem cell compartment. Brain 131 2564-2578.

Puymirat J, l'Hereault S \& Dussault JH 1992 Expression of thyroid hormone receptors mRNAs in rat cerebral hemisphere neuronal cultures. Brain Research. Developmental Brain Research 69 173-177.

Raff M 2006 The mystery of intracellular developmental programmes and timers. Biochemical Society Transactions 34 663-670.

Rodriguez M 2007 Effectors of demyelination and remyelination in the CNS: implications for multiple sclerosis. Brain Pathology 17 219-229.

Rodriguez-Pena A 1999 Oligodendrocyte development and thyroid hormone. Journal of Neurobiology 40 497-512.

Rogister B, Ben-Hur T \& Dubois-Dalcq M 1999 From neural stem cells to myelinating oligodendrocytes. Molecular and Cellular Neurosciences 14 287-300.

Rosser AE, Zietlow R \& Dunnett SB 2007 Stem cell transplantation for neurodegenerative diseases. Current Opinion in Neurology 20 688-692.

Rudick RA, Mi S \& Shandrock AW Jr 2008 LINGO-1 antagonists as therapy for multiple sclerosis: in vitro and in vivo evidence. Expert Opinion in Biology and Therapy 8 1561-1570.

Sanders P \& De Keyser J 2007 Janus faces of microglia in multiple sclerosis. Brain Research Reviews 54 274-285.

Schenker M, Riederer BM, Kuntzer T \& Barakat-Walter I 2002 Thyroid hormones stimulate expression and modification of cytoskeletal protein during rat sciatic nerve regeneration. Brain Research 957 259-270.

Sarlieve LL, Rodriguez-Pena A \& Langley K 2004 Expression of thyroid hormone receptor isoforms in the oligodendrocyte lineage. Neurochemical Research 29 903-922.

Schonberg DL, Popovich PG \& McTigue DM 2007 Oligodendrocyte generation is differentially influenced by toll-like receptor (TLR) 2 and TLR4-mediated intraspinal macrophage activation. Journal of Neuropathology and Experimental Neurology 66 1124-1135.

Setzu A, Lathia JD, Zhao C, Wells K, Rao MS, Ffrench-Constant C \& Franklin RJ 2006 Inflammation stimulates myelination by transplanted oligodendrocyte precursor cells. Glia 54 297-303.

Sher F, Balasubramaniyan V, Boddeke E \& Copray S 2008 Oligodendrocyte differentiation and implantation: new insights for remyelinating cell therapy. Current Opinion in Neurology 21 607-614.

Simons M \& Trotter J 2007 Wrapping it up: the cell biology of myelination. Current Opinion in Neurobiology 17 533-540.

Tauchmanovà L, Selleri C, De Rosa G, Esposito M, Di Somma C, Orio F, Palomba S, Lombardi G, Rotoli B \& Colao A 2005 Endocrine disorders during the first year after autologous stem-cell transplant. American Journal of Medicine 118 664-670.

Taylor PM \& Ritchie JW 2007 Tissue uptake of thyroid hormone by amino acid transporters. Best Practice and Research. Clinical Endocrinology and Metabolism 21 237-251.

Trentin AG 2006 Thyroid hormone and astrocyte morphogenesis. Journal of Endocrinology 189 189-197.

Tsui KH, Hsieh WC, Lin MH, Chang PL \& Juang HH 2008 Triiodothyronine modulates cell proliferation of human prostatic carcinoma cells by downregulation of the B-cell translocation gene 2. Prostate 68 610-619.

Visser WE, Friesema EC, Jansen J \& Visser TJ 2008 Thyroid hormone transport in and out of cells. Trends in Endocrinology and Metabolism 19 50-56. 
Williams GR 2000 Cloning and characterization of two novel thyroid hormone receptor $\beta$ isoforms. Molecular and Cellular Biology 20 8329-8342.

Wilson HC, Scolding NJ \& Raine CS 2006 Co-expression of PDGF $\alpha$ receptor and NG2 by oligodendrocyte precursors in human CNS and multiple sclerosis lesions. Journal of Neuroimmunology 176 $162-173$.

Wolswijk G 2002 Oligodendrocyte precursor cells in the demyelinated multiple sclerosis spinal cord. Brain 125 338-349.

Yang J, Rostami A \& Zhang GX 2009 Cellular remyelinating therapy in multiple sclerosis. Journal of the Neurological Sciences 276 1-5.
Yen PM 2001 Physiological and molecular basis of thyroid hormone action. Physiological Reviews 81 1097-1142.

Zoeller RT \& Rovet J 2004 Timing of thyroid hormone action in the developing brain: clinical observations and experimental findings. Journal of Neuroendocrinology 16 809-818.

Received in final form 16 June 2009

Accepted 30 June 2009

Made available online as an Accepted Preprint 3 July 2009 